\title{
Gene Therapy using Non-viral Gene Expression Vector and in vivo Electroporation for Bone Regeneration: Challenge to Gene Transfer into the Periodontal Tissues
}

\author{
Mariko Kawai, Kiyoshi Ohura \\ Osaka Dental University, Department of Pharmacology \\ 8-1Kuzuhahanazonocho, Hirakata City, Osaka, Japan 573-1121 \\ kawai-m@cc.osaka-dent.ac.jp
}

\begin{abstract}
It is well known that bone morphogenetic protein (BMP) induces ectopic bone formation when the recombinant protein or BMP gene is transferred into the skeletal muscle. In our previous studies, we developed a novel method for BMP gene transfer, which is combination with non-viral gene expression vector and in vivo electroporation. On the other hand, in the $B M P$ family, BMP-2/4 or BMP-2/7 heterodimer has stronger potential for bone induction compared with BMP-2, BMP-4 or $B M P-7$ homodimer. Then, we constructed BMP-2/7 heterodimer produced vector: $p C A G G S-B M P-2 / 7$. When we injected pCAGGS$B M P-2 / 7$ plasmid vector into the skeletal muscles and immediately performed in vivo electroporation, the ectopic bone formation was induced quickly on 10 days after gene transfer. For clinical application, we need more safe procedure on in vivo electroporation under the condition of lower voltage than 100 voltage. If we set the condition: 50 voltage and 8 pulses, the efficiency of gene transfer was also reduced by $50 \%$. But, when we induced pulse number, it recovered. We evaluated proper voltage and pulse number as the same gene transfer efficiency of 100 voltage. We often use bone prosthetic material and autogenous bone graft for alveolar bone defect caused by periodontal disease or trauma. But, these therapies sometimes have some risk for patients such as infection or fractures. In this study, we tried to apply this gene transfer system for alveolar bone regeneration of rats under the condition less 50 voltage. Our developed gene therapy system for alveolar bone regeneration will be with more safety and with fewer burdens on the patient in the future.
\end{abstract}

Keywords: Gene therapy, non-viral vector, in vivo electroporation.

(C) Copyright 2016 Authors - This is an Open Access article published under the Creative Commons Attribution License terms (http://creativecommons.org/licenses/by/3.0). Date Received: 2016-05-12

Date Accepted: 2016-07-20

Date Published: 2016-09-08
Unrestricted use, distribution, and reproduction in any medium are permitted, provided the original work is properly cited.

\section{Introduction}

BMP has strong potential to induce ectopic bone formation in the skeletal muscles when it is transplanted in the muscles $[1,2]$. For quarter century since recombinant human BMP (rhBMP) is constructed [3], rhBMP protein is not used for clinical application frequently $[4,5]$. Because rhBMP-2 protein is soluble and disperses soon after implantation, many researchers have used a matrix to retain the protein at the target site $[6,7]$. Gene-based delivery methods are generally divided into two categories: viral vectors and non-viral vectors $[8,9]$. Although adenoviral vectors are highly efficient for delivering BMP gene to the target muscles, there are several problems including the elicitation of an immune response in the host [10]. Therefore, we needed the treatment of immunosuppression by general or local to induce the ectopic bone formation in the skeletal muscles by the injection of BMP-2 gene expression adenoviral vector [11]. On the other hand, non-viral delivery methods (naked DNA, lipoplex, polyplex, and electroporation) do not need immunosuppression for successful gene delivery [10]. Electroporation can especially more rapidly express a target gene than virusmediated gene transfer, and it can increase the transfection rate by more than 100 -fold compared to the direct introduction of naked DNA [12]. In addition, gene therapy by in vivo electroporation is a simple and inexpensive method that only requires a plasmid and a device for performing electroporation. Therefore, we 
developed non-viral BMPs gene expression vector and tried to induce bone formation using in vivo electroporation [13]. BMPs family has several subtypes with high osteoinductive potential, and especially, BMP heterodimers as BMP-2/4 or BMP-2/7 have greater osteogenic potential than BMP homodimers [14, 15]. Then, we constructed BMP-2/BMP-7 heterodimer produced non-viral gene expression vector: pCAGGSBMP-2/7 and it induced ectopic bone formation in the skeletal muscles rapidly [16]. In vivo electroporation for clinical use requires safe condition under the lower voltage. Then, we searched lower voltage condition of electroporation for bone induction in the skeletal muscles keeping same gene transferred efficiency [17].

In this study, we tried to gene transfer using nonviral gene expression vector and in vivo electroporation under more safer conditions for clinical use on the goal of the alveolar bone regeneration.

\section{Material and Methods}

Directly or indirectly in vivo electroporation: to reveal whether directly or indirectly gene transfer was safer and less impaired, we measured creatine phosphokinase (CPK) in the skeletal muscles after gene transfer by in vivo electroporation. Nine-week-old male Wistar rats were purchased from Kurea (Osaka, Japan) and maintained under specific pathogen-free conditions in our animal facility. Rats were anesthetized by intraperitoneal injection of pentobarbital sodium (5.0 $\mathrm{mg} / 100 \mathrm{~g}$ of body weight). Non-viral vector, pCAGGSlacZ was injected into the skeletal muscles and immediately electroporated by plate type electrodes indirectly or by needle type electrodes directly on the condition of $50 \mathrm{~V}, 50 \mathrm{msec}$., 32 pulses. Twenty-four hours after the gene transfer, $0.1 \mathrm{~g}$ of the gene-transferred muscles was removed and homogenized at $12,000 \mathrm{rpm} / \mathrm{min}$ with $5000 \mu \mathrm{l}$. The supernatant was measured by $340 \mathrm{~nm}$ with CPK Assay Kit (Bio Assay Systems, CA, USA).

Making electrodes for periodontal tissues: we made the electrodes for the oral areas of the nine-week-old male Wistar rat using the system of dental impression (Fig. 1). Rats were anesthetized by intraperitoneal injection of pentobarbital sodium $(5.0 \mathrm{mg} / 100 \mathrm{~g}$ of body weight), and we took dental impression by silicon impression pate (Morita, Kyoto, Japan). Then, we made needle type electrodes, was directly applied on the periodontal tissues (figure 2).

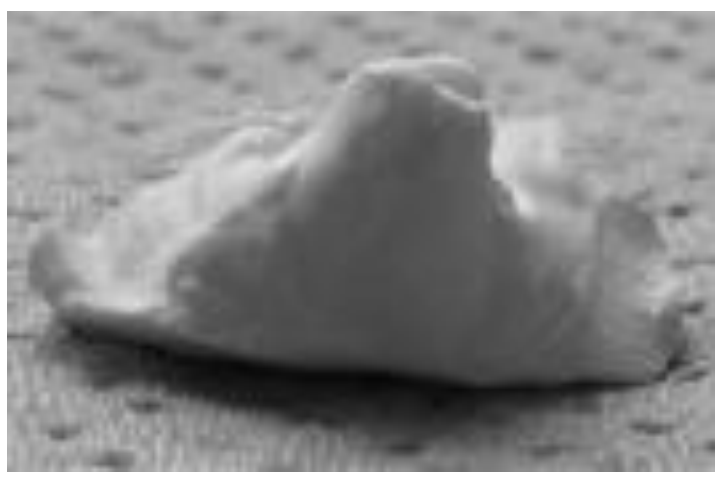

Figure 1. Making dental impression of rats.

Gene transfer to the periodontal tissues of rats: We tried to gene transfer into the periodontal tissues of rats using non-viral vector, pCAGGS-GFP and performed in vivo electroporation under low voltage conditions, $50 \mathrm{~V}$, $50 \mathrm{msec}$., 32 pulses. One day after gene transfer, we made histological samples and analyzed GFP expression by immunohistochemistry with antibody for GFP (Abcam, Cambridge, UK). All rats procedures were performed in accordance with Osaka Dental University guidelines (Approval No. 15-1001).

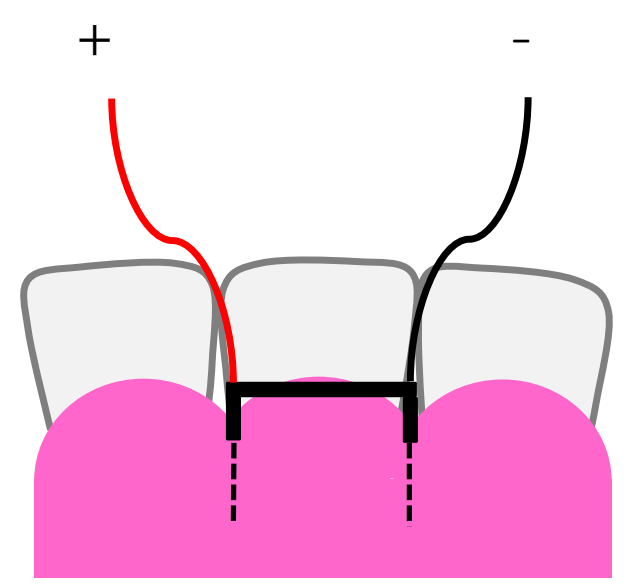

Figure 2. Needle type electrodes.

\section{Results}

One day after gene transfer to the skeletal muscles in rats, we detected significant higher CPK in the case of indirectly gene transfer with plate type electrodes than that of direct gene transfer with needle type electrodes (Figure 3). We revealed that direct gene transer with needle type electrodes could reduced tissue impaired compared with indirect gene tranfer with plate type electrodes. Therefore, we decided to make needle type electrodes for the periodontal tissues of rats (Figure 2). 


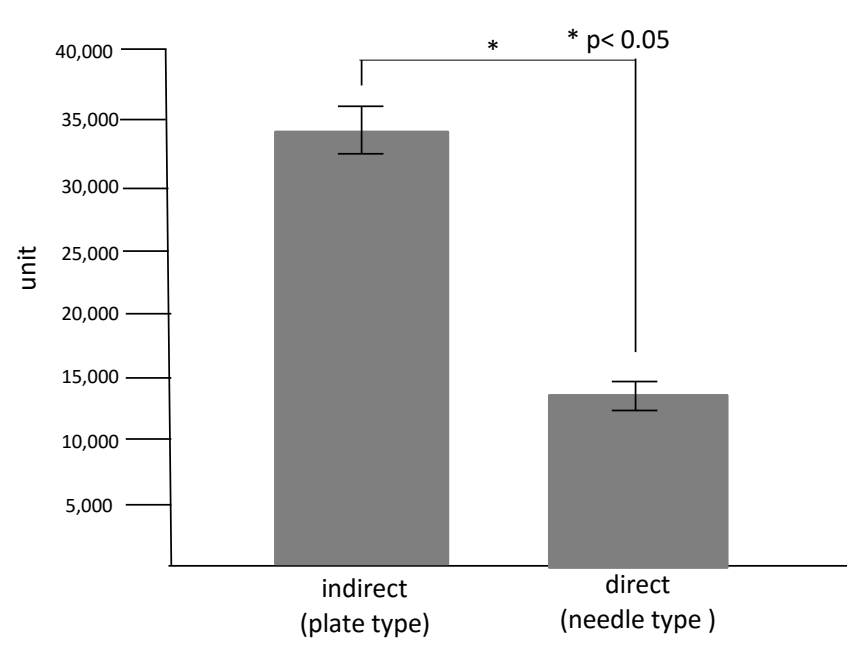

Figure 3. CPK after gene transfer.

Then, we could performe gene transfer and in vivo electroporation to the maxillary periodontal tissues of rats using the original electrodes by the dental impression system. One day after GFP gene transfer to the periodontal tissues of rats, we found GFP positive cells in the target areas (Figure 4. white arrowheads, scale bar $=100 \mu \mathrm{m}$ ).

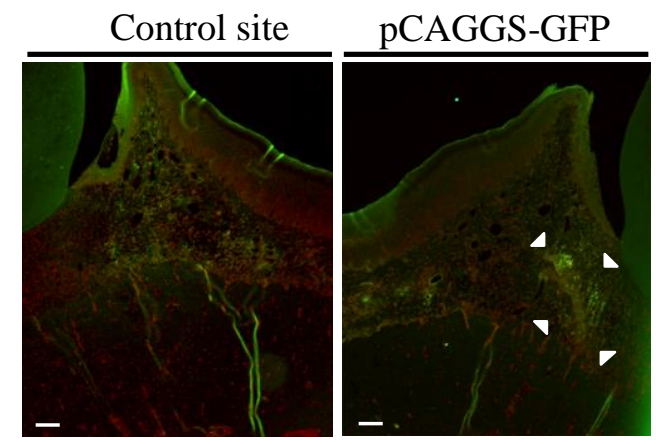

Figure 4. GFP gene transfer into the periodontal tissues.

\section{Discussion}

We could successfully performed gene transfer to the periodontal tissues using in vivo electroporation with needle type electrodes under the condition of less 100 Voltage. In this time, we chose the direct gene transfer to the periodontal tissues with needle type electrodes. When we measured CPK, which is a marker of muscle tissues impaired, direct gene transfer to the skeletal muscles with needle type electrodes was much less than indirect gene transfer with plate type electrodes. The needle type electrodes attached smaller areas of tissues than that of plate type electrodes. Therefore, needle type electrodes made less tissues impaired than plate type electrodes $[18,19]$. We transferred non-viral GFP gene expression vector to the maxillary periodontal tissues of rats under the condition of 50 voltage, $50 \mathrm{msec}$. and 32 pulses. One day after GFP gene transfer using in vivo electroporation, GFP positive cells were found in the areas of target site in the periodontal tissues of rats. On the other hands, we could not find GFP positive cells in the control site.

For future clinical use, less than 50 voltage condition for in vivo electroporation would be more safe and better. Therefore, we tried to achieve same efficiency of gene transfer as the condition with 50 voltage, $50 \mathrm{msec}$. and 32 pulses. When we performed in vivo electroporation with non-viral LaZ expression vector under the condition with 25 voltage, 200 msec. 8 pulses, the efficiency of gene transfer could be achieved at the same level of 100 voltage. The 25 voltage condition is almost same level with transcutaneous electric neural stimulation for temporomandibular joint disorder or myofacial pain $[20,21]$. Therefore, we would try gene transfer to the oral areas using in vivo electroporation under the condition with 25 voltage, 200 msec. and 8 pulses in the next stage for alveolar bone regeneration.

\section{Conclusion}

We successfully performed gene transfer to the oral areas using non-viral vector and in vivo electroporation. It is safe and simple methods. Therefore, the combination of non-viral gene expression vector and in vivo electroporation could be expected for bone regeneration therapy for clinical application in the near future.

\section{References}

[1] E. A. Wang, V. Rosen, J. S. D'Alessandro and M. Bauduy, "Recombinant human bone morphogenetic protein induces bone formation," Proc. Natl. Acad. Sci. U. S. A., vol. 87, pp. 2220-2224, 1990.

[2] K. D. Hankenson, K. Gagne and M. Shaughnessy, "Extracellular signalling molecules to promote fracture healing and bone regeneration," $A d v$. Drug. Deliv. Rev., vol. 94, pp. 3-12, 2015.

[3] J. M. Wozney, V. Rosen, A. J. Celeste, L. M. Mitsock and M. J. Whitters, "Novel regulators of bone morphogenetic protein: Molecular clones and activities," Science, vol. 242, pp. 1528-1534, 1988.

[4] A. Noshchenko, L. Hoffecker, E. M. Lindley, E. L. Burger, C. M. Cain and V. V. Patel, "Perioperative 
and long-term clinical outcomes for bone morphogenetic protein versus iliac crest bone graft for lumbar fusion in degenerative disk disease: systematic review with meta-analysys," J. Spinal Disord Tech., vol. 27, no. 3, pp. 117-135, 2014.

[5] A. W. James, G. LaChaud, J. Shen, G. Asatrian, V. Nguyen, X. Zhang, K. Ting and C. Soo, "A review of the clinical side effect of bone morphogenetic protein-2," Tissue Eng Part B Rev., vol. 22, no. 2, 2016.

[6] K. Bessho, D. L. Carnes, R. Cabin and J. L. Ong, "Experimental studies on bone induction using low molecular weight poly (DL-lactode-coglycolide) as a carrier fir recombinant human bone morphogenetic protein-2," J Biomed. Mater. Res., vol. 61, pp. 61-65, 2002.

[7] C. A. Tannoury and H. S. An, "Complications with the use of bone morphogenetic protein 2 (BMP-2) in spine surgery," Spine J., vol. 14, no. 3, pp. 552559, 2014.

[8] T. D. Alden, P. Varady, D. F. Kallmes, J. A. Jane and G. A. Helm, "Bone Morphogenetic protein gene therapy," Spin, vol. 27, pp. 87-93, 2002.

[9] T. Ogura, "In vivo electroporation: A new frontier for gene delivery and embryology," Differentiation, vol. 70, pp. 163-171, 2002.

[10] S. Chira, C. S. Jackson, I. Oprea, F. Ozturk, M. S. Pepper, I. Diaconu, C. Braicu, L. Z. Raduly, G. A. Calin and I. Berindan-Neagoe, "Progresses towards safe and efficient gene therapy vectors," Oncotarget, vol. 6, no. 31, pp. 30675-30703, 2015.

[11] S. Kaihara, K. Bessho, Y. Ohkubo, J. Sonobe, M. Kawai and T. Iizuka, "Simple and effective osteoinductive gene therapy by local injection of a bone morphogenetic protein-2-expressing recombinant adenoviral vector and FK506 mixture in rats," Gene Therapy, vol. 11, no. 5, pp. 439-447, 2004.

[12] M. Nishikawa and L. Huang, "Non viral vectors in the new millennium: Delivery barriers in gene transfer," Human Gene Therapy, vol. 12, pp. 861870, 2001.

[13] M. Kawai, K. Bessho, S. Kaihara, J. Sonobe, K. Oda, T. Iizuka and H. Maruyama, "Ectopic bone formation by human bone morphogenetic protein2 gene transfer to skeletal muscle using transcutaneous electroporation," Human Gene Therapy, vol. 14, pp. 1547-1556, 2003.
[14] D. I. Isrel, J. Nove, K. M. Kerms, R. J. Kaufman, V. Rosen, K. A. Cox and J. M. Wozney, "Heterodimers bone morihogenetic protein show enhanced activities in vitro and in vivo," Growth Factor, vol. 13, pp. 291-300, 1996.

[15] T. Morimoto, T. Kaito, Y. Matsuo, T. Sugiura, M. Kashii, M. Iwasaki and H. Yoshikawa, "The bone morphogenetic protein-2/7 heterodimer is a stronger inducer of bone regeneration than the individual homodimers in a rat spinal fusion model," Spine J., vol. 15, no. 6, pp. 1379-1390, 2015.

[16] M. Kawai, H. Marumaya, H. Yamamoto, K. Bessho, J. Miyazaki and T. Yamamoto, "Simple strategy for bone regeneration with a BMP-2/7 gene expression cassette vector," $B B R C$, vol. 390, pp. 1012-1017, 2009.

[17] H. Yamamoto, M. Kawai, N. Shiotsu, M. Watanabe, Y. Yoshida, K. Suzuki, H. Maruyama, J. Miyazaki, M. Ikegame and T. Yamamoto, "BMP-2 gene transfer under various conditions with in vivo electroporation and bone induction," $A$. J. Oral Maxillo. Surg., vol. 24, pp. 49-53, 2012.

[18] Z. Wei, S. Zheng, R. Wang, X. Bu, H. Ma, Y. Wu, L. Zhu, Z. Hu, Z. Liang and Z. Li, "A flexible microneedle array as low-voltage electroporation electrodes for in vivo DNA and siRNA delivery," Lab Chip., vol. 14, pp. 4093-4102, 2014.

[19] L. M. Mir., "Electroporatoin-based gene therapy: recent evolution in the mechanism description and technology developments," Methods Mol Biol., vol. 1121, pp. 3-23, 2014.

[20] J. Boever and W. D. McCall, "Aspects of masticatory muscle stimulation: the myomonitor," Quitessence Int., vol. 3, pp. 57-58, 1972.

[21] U. S. Pal, L. Kumar, G. Mehta, N. Singh, M. Singh and H. K. Yadav, "Trends in management of myofacial pain," Natl. J. Maxillofac. Surg., vol. 5, no. 2, pp. 109116, 2014. 